\title{
Práticas colaborativas em redes agroecológicas no agreste pernambucano
}

DOI

http://dx.doi.org/10.11606/ 2179-0892.ra.2018.145526

\section{Pedro Castelo Branco Silveira}

\section{e Júlia Costa Rosas}

- Fundação Joaquim Nabuco | Recife, PE, Brasil;

- Universidad Internacional de Andalucia | Baeza, Espanha

$\boldsymbol{\nabla}$ pedrocbsilveira@gmail.com, julia.crosas@gmail.com

\section{RESUMO}

Este artigo aborda as contribuições das redes agroecológicas para os debates sobre $o$ acesso aos conhecimentos tradicionais. O material empírico que trazemos é o de pesquisa no agreste pernambucano, sobre as redes de produção de conhecimento de que fazem parte agricultores que desenvolvem práticas agroecológicas. Neste campo, agricultores e organizações de assessoria estão envolvidos em uma série de experiências que se baseiam na incorporação de conhecimentos dos agricultores, de técnicos e em testes e experimentos, não necessariamente em bases científicas, de novas práticas agrícolas. O pano de fundo destas experiências é o fortalecimento de propostas ecopolíticas conhecidas como "convivência com o Semiárido" que se afastam de pacotes tecnológicos e se aproximam de modos criativos e colaborativos de praticar conhecimentos. 


\section{INTRODUÇÃO'}

A ecologia política das práticas agrícolas é perpassada por diversos dilemas relativos à produção e circulação de conhecimentos. Há, por um lado, um debate em curso a respeito das apropriações e regulamentações dos chamados conhecimentos tradicionais. Esse debate se relaciona à natureza dos conhecimentos tradicionais (Nygren, 1999; Ingold e Kurtilla, 2000; Carneiro da Cunha, 2009; Silveira, 2011) e às formas de proteção de tais conhecimentos face às investidas de mercantilização (Strathern et al., 1998; Kishi e Kleba, 2009; Carneiro da Cunha, 2009), incluindo a proposição de mecanismos sui generis de direitos para tais conhecimentos (Santilli, 2005), que se diferenciem dos regimes de propriedade industrial e propriedade intelectual vigentes, e que impliquem em formas de "repartição equitativa dos benefícios oriundos da utilização desse conhecimento, inovações e práticas", como posto no artigo 8j da Convenção da Diversidade Biológica.

Em uma linha paralela correm debates sobre o futuro da agricultura familiar, em que propostas do tipo agroecológico ganham força. Neste campo, agricultores, organizações de assessoria e acadêmicos estão envolvidos em uma série de experiências que se baseiam na incorporação de conhecimentos dos agricultores, de técnicos e em testes e experimentos, não necessariamente em bases científicas, de novas práticas agrícolas (Hocdé, 1999; Sabourin, 2001). O pano de fundo destas experiências seria a concretização de propostas agrícolas do tipo "sustentável" que, se afastando de pacotes tecnológicos, e aproximando-se de formas tradicionais de práticas agrícolas, sugeririam novos rumos à agricultura (Altieri e Toledo, 2011). Tais iniciativas trazem consigo formas próprias de produção e circulação de conhecimentos e de espécies, além de formulações próprias dos sujeitos que delas participam sobre como esta deve ocorrer.

A formação de redes colaborativas de conhecimentos, incentivadas por organizações de assessoria, é uma característica marcante de parte das experiências agroecológicas de agricultores familiares. As instituições assessoras, em geral organizações não-governamentais de pequeno porte com histórico de trabalho conjunto com movimentos sociais, sindicatos e organizações de trabalhadores, buscam, no contexto brasileiro, desenvolver modos de atuação que partam das formas de produção de conhecimento costumeiras dos agricultores, reforçando dimensões como a da sustentabilidade e da experimentação². Em Pernambuco há uma série de organizações assessoras em agroecologia, entre elas o Serviço de Tecnologia Alternativa (Serta), a Federação de Órgãos para Assistência Social e Educaciona (Fase), a Diaconia, o Caatinga e o Centro Sabiá, entre outros.

Este tipo de interação faz emergir o conceito de "agricultores-experimentadores", ou seja, aqueles agricultores que criam novidades a partir de suas práticas de conhecimento. A organização Assessoria e Serviços a Projetos em
1 Uma versão preliminar deste texto foi apresentada na $28^{\mathrm{a}}$ Reunião Brasileira de Antropologia, em 5 de julho de 2012. Os autores agradecem aos agricultores agroecológicos de Cumaru que nos receberam, ao Centro Sabiá pelo apoio na articulação e à Fundação Joaquim Nabuco pelo financiamento da pesquisa. Agradecem também aos comentários de Dominique Gallois, Geraldo Andrello e Edilene Cofacci de Lima à versão preliminar do artigo e às observações dos dois pareceristas anônimos que contribuíram para sua forma final.

2 Grande parte das organizações de agricultores e instituições de assessoria que atuam sob esta perspectiva formam a Articulação Nacional de Agroecologia, formada a partir do primeiro Encontro Nacional de Agroecologia, que ocorreu em 2002 no Rio de Janeiro. 
Agricultura Alternativa (AS-PTA) é historicamente uma das responsáveis pela disseminação da ideia de agricultores-experimentadores no Brasil, articulando-se, no caso do Nordeste, com a forte experiência dos sindicatos de trabalhadores rurais referenciados pelas ligas camponesas dos anos de 1960 e com as organizações católicas referenciadas pela Teologia da Libertação (Sabourin, 2009).

Neste artigo apresentamos o caso de um grupo de agricultores agroecológicos no Agreste pernambucano, indicando de que forma se produzem e circulam conhecimentos nas redes colaborativas formadas pelas práticas agroecológicas, e indicando como se situam as noções de experimentação, criatividade e inovação nestas redes. Mais do que uma descrição sociológica de uma rede de atores nas práticas agroecológicas (o que seria em si uma abordagem possível e relevante), buscamos aqui perceber as formas pelas quais os agricultores praticam o acesso ao conhecimento em suas redes de relações. Assim, buscamos indicar contribuições das redes agroecológicas para os debates sobre o acesso aos conhecimentos tradicionais acerca da biodiversidade.

As histórias aqui contadas inserem-se num panorama regional pautado pelo debate sobre o futuro do chamado Semiárido nordestino. O Semiárido constitui um recorte geopolítico que abrange um mosaico socioambiental em que convergem um clima (seco com ocorrência extremamente irregular de chuvas), um bioma (conjunto de diferentes fisionomias vegetais que compõem a caatinga) e modos de vida humanos (sertanejos) de habitar essas paisagens (Ab'Saber, 2003).

Percebe-se na região, desde o início da década de 1990, o fortalecimento de uma proposta política denominada convivência com o semiárido, levada a cabo por sindicatos e associações de trabalhadores rurais e organizações não-governamentais do tipo descrito acima. Tal perspectiva, com o tempo, passou a incluir-se, ainda que de maneira tímida, em ações dos poderes públicos federal, estaduais e municipais. A rede de práticas de conhecimento da convivência com o semiárido vem a se contrapor a uma perspectiva que há muito guia as políticas públicas na região: aquela que considera que o problema dos seus moradores é a seca, que, por sua vez, seria solucionada com a realização de grandes obras. Essa perspectiva de combate à seca pautou a criação dos polos de agricultura irrigada bem como a instalação de usinas hidrelétricas no Rio São Francisco décadas atrás. Já a noção de convivência com o semiárido parte da perspectiva de que há diversos modos, produzidos localmente, de se desenvolver para viver saudavelmente em um clima semiárido, passando principalmente pela valorização da caatinga no combate à desertificação e pelo desenvolvimento de estratégias de captação e manutenção da água pluvial (Duque, 2008).

No período desta pesquisa, a oposição entre o modelo de combate à seca e o de convivência com o semiárido era claramente representado, respectivamente, pela oposição entre grandes projetos de infraestrutura como a Transposição do 
Rio São Francisco, por um lado e, por outro lado, pela ação de uma rede de movimentos sociais chamada Articulação do Semiárido, que atuava politicamente em prol das práticas de conhecimento do tipo das que descreveremos etnograficamente a seguir.

\section{AGROECOLOGIA E CONVIVÊNCIA COM O SEMIÁRIDO: O CASO DE CUMARU}

No ano de 2012 o Semiárido nordestino passou pela a pior seca desde os anos de 1980. Mesmo no Agreste, zona semiárida heterogênea que apresenta restrição hídrica menos severa que o chamado Sertão, os agricultores se encontravam preocupados com a grave estiagem. No pequeno município agrestino de Cumaru, de aproximadamente 17 mil habitantes e perfil eminentemente rural, encontramos o casal Joelma e Roberto, agricultores familiares que partilham desta preocupação. Não é tempo de plantio ou de colheita de culturas agrícolas. Estamos no mês de abril e a última chuva, isolada, ocorreu em fevereiro. Apesar disso, Roberto produz queijo coalho com o leite das duas vacas bem cuidadas que possuem no curral, a despensa da família está cheia de garrafas do mel de abelhas produzido durante o ano, as galinhas, patos, galinhas d'angola e perus estão gordos no galinheiro, há um canteiro de hortaliças em plena atividade e não falta água em sua propriedade de 7 hectares - pelo menos por enquanto.

Joelma é membro da diretoria do Sindicato dos Trabalhadores Rurais de Cumaru e articula diversas ações agroecológicas no município. No momento em que a pesquisa de campo era realizada, formalizava-se a Associação dos Agricultores e Agricultoras Agroecológicos de Cumaru (Associagro), que já existia como rede não-formal havia alguns anos. Roberto, além do trabalho cotidiano na manutenção da propriedade, é reconhecido como bom construtor de cisternas de armazenamento de água da chuva, e de tempos em tempos atua na construção destas no município e em outros municípios da região.

O armazenamento de água da chuva é, atualmente, a mais importante estratégia de adaptação dos moradores das áreas rurais do Nordeste semiárido, por conta da distribuição irregular de chuvas ao longo do ano. A presença de água armazenada garante o uso doméstico e, se em maior quantidade, a manutenção de criação animal e de plantas que não são nativas da caatinga. Armazenar água há muito faz parte das preocupações dos moradores do semiárido nordestino e, como veremos, no período da pesquisa sua promoção encontra-se institucionalizada.

Nesse sentido, um dos motivos da situação mais confortável de Roberto e Joelma neste momento de seca é a capacidade que possuem de armazenar águas pluviais. A família possui cinco estruturas de armazenamento de água: uma cisterna de placas de cimento, para todo o uso doméstico, com capacidade de 16 mil litros, que capta a água da chuva que escorre pelo telhado da casa; 
uma cisterna do tipo calçadão, com capacidade para 52 mil litros, usada para produção; uma cisterna de 22 mil litros utilizada para criação de animais; uma barragem subterrânea, utilizada para produção agrícola; e um barreiro, que hoje é utilizado principalmente para os animas ${ }^{3}$.

A história da construção destas estruturas é representativa da trajetória do casal. Até 2004 , sua propriedade tinha 0,5 hectare e a única água disponível era a do barreiro, que era utilizada para todos os fins. Em 2004 surgiu a possibilidade de construção da primeira cisterna de placas, a de consumo doméstico. A construção foi possível pelo estabelecimento do Programa "Um Milhão de Cisternas" (P1MC). Neste período, Roberto capacitou-se, como parte do programa, como pedreiro construtor de cisternas. Abaixo, Joelma nos narra este processo.

Roberto fez o curso de pedreiro, de cisterneiro. (...) A primeira cisterna que ele fez foi a da gente, foi essa daqui. (...) Aí Roberto começou a fazer cisterna, participando de curso, melhorando, se aperfeiçoando. (...) Depois foi havendo a necessidade de mais gente para construir. Roberto e outro menino daqui ensinaram eu acho que a umas dez pessoas. (...) Aí Roberto foi fazendo isso e foi dando curso de pedreiro, ou cisterneiro, como o povo conhece. E por curso você ganhava o mesmo tanto de construir uma cisterna. Porque quem estava aprendendo construía, você ensinava, também participava da construção, mas fazia rápido, porque eram cinco ou seis pessoas, dez pessoas, numa cisterna só, para aprender. Eo instrutor do curso, que era a pessoa que já sabia, ganhava o valor da cisterna que estava sendo construída pelos aprendizes. (Joelma, dezembro de 2011)

O envolvimento no Programa "Um milhão de Cisternas" abriu uma série de perspectivas para a família de Joelma e Roberto. O fragmento de entrevista acima mostra como a prática de Roberto construir cisternas o tornou referência para outras pessoas da região, permitiu que o casal armazenasse água para produção e permitiu ainda um incremento de renda que propiciou que aumentassem o tamanho de sua propriedade de 0,5 hectares para 7 hectares (segundo Joelma, 0 tamanho médio de uma propriedade de agricultura familiar na região é de 4 a 5 hectares). Com isso, reordenaram sua produção e construíram paulatinamente as demais cisternas na propriedade, beneficiadas agora por uma segunda fase do P1MC, que se chama P1+2 (“Uma terra, duas águas"). A cisterna de 22 mil litros foi construída autonomamente por Roberto, independente do P1MC.

Vale aqui uma nota sobre o P1MC. O programa foi criado a partir do estabelecimento da rede Articulação do Semiárido (ASA) em parceria com o Governo Federal no início do primeiro mandato do então presidente Lula, em um momento em que a recém-empossada Ministra do Meio Ambiente Marina Silva propunha como política do Ministério dar escala a iniciativas bem-sucedidas dos movi-
3 A cisterna calçadão é um modelo de cisterna que aproveita a água pluvial que escorre em uma superfície impermeabilizada, tendo uma capacidade maior que uma cisterna de abastecimento doméstico; uma barragem subterrânea é estrutura que objetiva barrar o fluxo subterrâneo de um aquífero preexistente ou criado concomitantemente à construção de uma barreira impermeável; um barreiro é um reservatório simples que capta a água das chuvas a partir de seu escoamento superficial no solo e armazena-a para utilização posterior. 
mentos sociais (Duque, 2008). A construção das cisternas, portanto, constituiu uma política pública articulada a partir da noção de convivência com o semiárido ${ }^{4}$. É comum que os beneficiados sejam assessorados pelas organizações parceiras a estabelecerem práticas desta natureza, a partir da captação de água. fruto de tais articulações, insere-se numa linha de atuação política dos movimentos sociais no semiárido nordestino denominada convivência com o semiárido (Pinto, 2004).

Importa-nos, no contexto deste trabalho, que a possibilidade de armazenar água por meio das cisternas propiciou o envolvimento do casal Joelma e Roberto com as chamadas práticas agroecológicas. A organização responsável pela articulação do $\mathrm{P}_{1} \mathrm{MC}$ e $\mathrm{P}_{1}+2$ na região, em colaboração com o Sindicato dos Trabalhadores Rurais e a Igreja Católica, foi o Centro de Desenvolvimento Agroecológico Sabiá, uma organização não-governamental pernambucana que tem como eixo de atuação o incentivo à produção agroecológica baseada na agricultura familiar, que assessora agricultores em diversas regiões do estado de Pernambuco. A organização existe desde 1993, mas passou a trabalhar na região de Cumaru a partir de 2004, como desenvolvimento do P1MC. Prosseguimos abaixo com a narrativa de Joelma.

A partir da chegada dessa cisterna, que veio via comissão, quem gerenciou foi o Sabiá, que tinha um representante de Igreja, representante do Sindicato, um bocado de gente na comissão que escol hia as comunidades. Aí, 'vamos reunir o pessoal da comunidade tal', aí juntava o povo lá no grupo ou juntava o povo lá onde tinha um local, eles convidavam as famílias, as famílias iam, levavam a documentação e se cadastravam. Por aqueles critérios, a comissão selecionava e dizia: família tal, família tal e família tal. Aí o técnico do Sabiá, por aquelas informações que tinha no cadastro, visitava a casa, marcava o buraco para cavar, essas coisas todas. Aí foi a partir daí que a gente teve acesso a cisterna. (Joelma, entrevista em abril de 2012).

Joelma conta que antes deste período ela mesma não tinha uma participação política ou comunitária além de sua inserção nas atividades religiosas da Igreja Católica. A partir de seu envolvimento no P1MC, fazendo um curso de "gestão de recursos hídricos", que fazia parte do ritual para o beneficiários das cisternas, Joelma passou a colaborar no processo de cadastro das famílias e solicitou ao Centro Sabiá que organizasse uma visita de intercâmbio a uma família de agricultores que eram assessorados pela organização, no município de Bom Jardim. Seguimos com o relato de Joelma.

Na época a gente convidou umas famílias (...) e aí a gente fez essa visita: marcamos um dia, convidamos os agricultores e fomos, 12 pessoas, de cada casa uma
4 Ao longo do $\mathrm{P} 1 \mathrm{MC}$, as organizações constituintes da Articulação do Semiárido passaram a articular outros financiamentos para construção de cisternas para além dos ofererecidos pelo Governo Federal, tais como a Federação Brasileira de Bancos (Febraban), entre outros. No final de 2011 o Governo Federal anunciou o corte no financiamento do P1MC, o que causou indignação em todo o Semiárido. Esta questão ainda está sendo negociada no período em que este artigo é escrito. Em maio de 2012 o Governo do Estado de Pernambuco, por sua vez, anunciou a destinação de fundos para a construção de cisternas. 
pessoa, para dar a chance de várias famílias irem, pelo menos um representante de cada família, para conhecer essa experiência lá em Bom Jardim, que lá já tinham uns agricultores que desde 98 que estavam trabalhando desse jeito. A gente foi. Chegamos lá, visitamos uma área muito parecida com a da gente, bem seca, de um agricultor, edepois fomos para uma área mais brejeira, que tinha mais água e ele tinha um riacho que passava e essas coisas todas. Aí, quando a gente voltou, dos 12 que foram pra lá pra visita, eu comecei, em casa, na briga, na discussão, discussão de dizer: 'vamos fazer desse jeito, que lá em Seu Cláudio e Dona Teresa, eu vi dessa forma. Porque também a gente não faz? E lá é seco como aquié seco.' Aí a gente começou. (Joelma, entrevista em abril de 2012).

Neste período o casal plantava apenas palma e cultivos anuais como milho e feijão, além de criar pequenos animais, em seu meio hectare de terra. A partir do intercâmbio promovido pelo Centro Sabiá, Joelma e Roberto passaram a diversificar o plantio, promovendo um regime de produção do tipo agroecológico. $O$ aumento da propriedade permitiu reorganizá-la, tendo maior autossuficiência na alimentação dos animais, recuperando a fertilidade do solo e investindo em apicultura. Os três fragmentos da entrevista com Joelma e Roberto abaixo narram este processo de diversificação do plantio e reorganização espacial da propriedade:

Depois que a gente ganhou a cisterna, aí a gente disse: 'não, não vamos plantar assim, não vamos ter só palma não'. Porque a palma supera um pouco da ração do gado ou das ovel has, que a gente criava, no verão. Mas e as outras coisas? Ela não só come palma! Vamos plantar outras coisas também, porque no curso da cisterna o povo disse que tinh a possibilidade de se plantar junto, e a terra não podia ficar nua, e o interessante era se você pudesse cobrir ela, que ela produzia mais, que ela ia se recuperando se ela fosse uma terra fraca, que se você contribuísse também, ela produzia mais depressa e uma quantidade maior de coisas. Se você cuidasse. Aí a gente carregou muito saco de folha seca que aqui não tinha, subia aquela ladeira, a gente foi aos poucos plantando estaca, plantando semente e botando as mudinhas nesses buracos que a gente cavou e colocava com folhas. (Joelma, entrevista em novembro de 2011).

No começo a gente só plantava milho e feijão, depois a gente plantou uma variedade de coisas. Tem as frutas, que mesmo pouco que está dando, dá, ajuda. A gente planta fava, um bocado de qualidade de feijão, a gente planta. A gente não plantou muito esse ano que esse ano foi todo a trapalhado, mas a gente sempre lucra muito feijão pardo, fava, milho de pipoca, milho para as galinhas, guandu (...) Macaxeira, que a gente não plantava. Cergelim...girassol, que a galinha 
gosta muito de girassol... (Roberto, entrevista em novembro de 2011).

Todas as áreas que a gente tem é uma mistura. Não sei se tujá percebeste. Aqui meio hectare próximo à casa tem criação, tem plantação, tem canteiro, é uma mistura. Na segunda área a gente tem uma área de manejo de planta nativa, a gente tem a criação de abel ha, a gente tem criação de galinha, mas não deixa de ter também uma área separada que a gente faz um roçado que a gente chama de roçado diversificado, que é quando a gente faz o plantio de várias culturas no mesmo local. E tem a terceira área, que a gente tem criação, no açude, dos peixes, tem a barragem que a gente tem aquela diversificação toda, e tem uma área mais descoberta que é onde a gente solta os animais. Planta durante o inverno, que é a cultura de ciclo curto, que é sorgo, milho, feijão, e durante o verão a gente solta as vacas lá. (Joelma, entrevista em novembro de 2011).

Ser beneficiário de uma cisterna, obviamente, não significa engajar-se automaticamente em iniciativas agroecológicas. Das primeiras famílias que foram contempladas com as cisternas de abastecimento doméstico, e que visitaram os agricultores de Bom Jardim, apenas a de Joelma passou a se auto-definir como agricultores agroecológicos. Em verdade, Joelma transformou-se na principal figura de referência em agroecologia no município, e no período da pesquisa trabalhava associada ao Sindicato dos Trabalhadores Rurais.

Roberto e Joelma, entretanto, não são isolados nas práticas agroecológicas no município, pelo contrário. Há uma rede de famílias que constitui o grupo agroecológico que se formalizava como associação durante a pesquisa de campo. São pessoas que também foram beneficiadas com cisternas, mas que, como diz Joelma, "foram se achando com o jeito que a gente estava trabalhando". Foi o caso do senhor Luís. Convidado por Joelma, foi a uma capacitação promovida pelo Sabiá, e depois participou de alguns intercâmbios com visitas a outros agricultores em outros locais do semiárido nordestino.

Joelma e Luís relacionam treze famílias no grupo dos agricultores agroecológicos de Cumaru, pertencentes a cinco localidades do município. Pedra Branca, local onde moram Roberto e Joelma, é o local de moradia também de outras sete famílias do grupo. Entre os adultos, Luís é o mais idoso participante do grupo, com 62 anos. O participante mais novo tem 21 anos. Segundo nos contaram Joelma e Luís, a entrada deste no grupo se relaciona com a percepção que Joelma teve de sua sensibilidade para as questões que a agroecologia levantava. Uma outra família, de um local chamado Jurema, aproximou-se posteriormente ao grupo após ter sido contemplada com uma cisterna. As demais nove famílias participantes, em níveis diferentes de envolvimento, tinham, além da participação no P1MC, relações de parentesco com Roberto (os irmãos de Joelma muda- 
ram-se para Recife), sendo irmãos/irmãs, cunhados/cunhadas ou sobrinhos/ sobrinhas. Isto nos indica que as redes costumeiras de relações sociais presentes em Cumaru são importantes para definir as redes agroecológicas em conformação. Mas as práticas agroecológicas ampliam as redes de relações do grupo, pois também tecem redes para além do município (e do estado) propiciadas pela interlocução com o Centro Sabiá, que por sua vez se conecta a rede de convivência com o semiárido.

\section{INTERCÂMBIOS E INOVAÇõES}

Descrevemos acima a constituição de uma rede local de agricultores agroecológicos que se articula com uma rede mais ampla de convivência com o semiárido, da qual um dos principais motores é a difusão das tecnologias de armazenamento de água, em especial as cisternas de placa. Propositalmente destacamos esta rede de agricultores de suas múltiplas demais relações de sociabilidade humana, que não abordaremos aqui, pois nossa intenção é discutir as formas específicas pelas quais os conhecimentos são praticados por meio destas relações. Nos debrucemos agora sobre tais práticas de conhecimento. Como se praticam conhecimentos nesta rede.

Luís nos conta que a forma de lidar com a terra na região, desde sua infância, teve transformações. Narra a história agrária local como a de pequenos proprietários envolvidos na criação de gado, utilizando um sistema que envolvia o plantio de palma (cacto forrageiro e alimentício originário da América Central e resistente às secas severas), o uso de vegetação nativa como forragem e o consórcio de milho e feijão como plantio anual nos tempos de chuva.

A estrutura agrária existente, de minifúndios bem delimitados, contrasta com formas de uso mais extensivas e comunais encontradas em outras regiões do semiárido, tais como os fundos de pasto do São Francisco baiano (Sabourin et al, 1999), que não existem em Cumaru e no Agreste em geral. A narrativa de Luís envolve uma mudança na agricultura da região durante o século XX, com a expansão do plantio do algodão arbóreo em sistema de monocultura, com grande utilização de agrotóxicos. Após a massificação do plantio de algodão, o inseto bicudo se alastrou como praga dos algodoais do semiárido. A praga do bicudo, segundo Seu Luís, fez declinar a economia do algodão na região, mas a prática generalizada do uso de agrotóxicos na agricultura, introduzida naquele período por técnicos agrícolas do Coverno do Estado, continua até os dias de hoje.

Face a este histórico, as práticas de convivência com o semiárido introduzidas a partir a atuação do Centro Sabiá e do P1MC vem a trazer uma série de novas técnicas, diversas das práticas de agricultura moderna, representadas pelos pacotes tecnológicos e também diferentes das práticas costumeiras que se modificaram 
e persistiram após a introdução de técnicas modernas. Antes de entrarmos na discussão da natureza dessas diferenças, tentemos entender um pouco melhor como são os conhecimentos praticados nestas redes.

As narrativas de Joelma e Roberto nos indicam que a diversificação da produção é uma das principais diretrizes nesta rede agroecológica. Na entrada de sua propriedade vemos uma área em que se mesclam plantas nativas e introduzidas que podem ser usadas como frutíferas, melíferas e forrageiras, ou que não têm uso imediato mas foram preservadas ao nascerem espontaneamente. 0 mesmo tipo de sistema que encontramos na propriedade de Nivá, irmão de Roberto, que também faz parte do grupo. Nivá especializou-se no plantio de cajus, mas em seu talhão agroflorestal os cajueiros conviviam com outras plantas frutíferas, nativas e melíferas, entre outras. Em praticamente todas as casas de membros do grupo agroecológico que visitamos havia o chamado canteiro econômico, uma modalidade de canteiro de produção de hortaliças que é construído de maneira simples e é adaptado ao semiárido por aproveitar melhor a água despendida.

O canteiro econômico, assim como uma máquina caseira para trançar telas de arame e a fabricação de venenos naturais a partir da fermentação de plantas como a maniçoba e o feijão de boi, é uma das técnicas que passaram a fazer parte das práticas de conhecimento dos agricultores a partir da construção de cisternas. Poder-se-ia argumentar que a introdução destas novas técnicas por meio de assessoria constituísse um projeto do tipo colonizador, da mesma forma como o são os pacotes tecnológicos agroquímicos trazidos pelos agrônomos convencionais, mas não é isto que verificamos. Examinemos como estas técnicas são aprendidas pelos agricultores e como se difundem.

Há pelo menos quatro circuitos experienciais de aprendizado de novidades no contexto da assessoria do Centro Sabiá aos agricultores de Cumaru: o primeiro são as capacitações promovidas pelo Centro Sabiá, em formas de cursos teórico-práticos ministrados pelos técnicos e/ou por agricultores que se tornaram referência. O segundo são os intercâmbios, situação na qual um grupo de agricultores viaja para conhecer experiências de outros agricultores (como relatamos acima a respeito da viagem a Bom Jardim realizada pelos agricultores beneficiados por cisternas em Cumaru), ou quando um agricultor considerado referência viaja para outro município e passa alguns dias assessorando os outros agricultores em uma técnica que este domina. O terceiro circuito é a assessoria direta do técnico aos agricultores, que, segundo a própria metodologia do Centro Sabiá, é mais intensiva no início do acompanhamento e depois torna-se mais esparsa visando a autonomia do grupo. E o último circuito é o da difusão direta de agricultor para agricultor na mesma localidade, por meio das relações costumeiras.

Os agricultores agroecológicos de Cumaru afirmam em uníssono que os 
intercâmbios são a melhor forma de conhecer novidades. Vejamos este depoimento de Luís:

[Visitamos] várias comunidades. Soledade na Paraíba. Que era um técnico que nós tínhamos, que nos acompanhava, Garibaldi, que até Caribaldi, brincando com a gente, disse 'Olhe, vocês vão pegar uma época lá tão seca, tão seca, que não tem água. A gente para tomar banho tem que cuspir um no outro.' E chegamos lá, era seco mesmo, muito seco. Mas quando chegamos na barragem subterrânea, nós vemos as coisas diferentes. Nós chegamos na barragem subterrânea de um cidadão, e ele mostrou o canteiro econômico. Canteiro, uma hora dessa, o sol quente que ninguém aguentava. Foram umas mulheres para lá, não tinham chapéu, tiveram que improvisar um chapéu lá. O sol era quente que ninguém aguentava. A pastagem que nós víamos lá só xiquexique, mandacaru, facheiro, só coisa mesmo do sertão, pau seco. Mas umbu, verde. Juá, verde. Aí foi onde nós vimos a produção, o beneficiamento do umbu. O beneficiamento do facheiro. O beneficiamento da fruta de palma. Uns frutinhos que eu tenho ali, não sei se Joelma trouxe. Trouxemos porque o homem disse que o nome dela é cumbeba, aí eu disse: 'Oxe, como é que faz isso aqui?', 'A gente faz aqui o suco, com leite.' $E$ quando botou na mesa eu disse: 'Olhe, isso aqui é o viagra do sertão'. Serviu até como brincadeira. Aí todo mundo depois se interessou e trouxe, porque aqui não tinha. Mas depois descobrimos que alguns cantos por aqui têm. (Luís, entrevista em abril de 2012).

Os intercâmbios são valorizados porque propiciam a troca de experiência de agricultor para agricultor para além do âmbito local e, segundo os entrevistados, mais do que as capacitações, permitem que os conhecimentos sejam praticados nos formatos costumeiros dos agricultores.

Então cada um chegava e perguntava: "mas e isso assim e assim? Onde é que você consegue a semente? Como é que você consegue? Como é que você faz para ela germinar?". Entendeu? Então, toda curiosidade é de agricultor para agricultor. O intercâmbio é uma troca de experiência, com uma linguagem própria. (Luís, entrevista em abril de 2012).

Por meio destas novas práticas de conhecimento, os agricultores parecem produzir novas habilidades (Ingold, 2000) nas suas práticas agrícolas costumeiras. Fazendo circular tais práticas de modo criativo por meio do contato entre agricultores. Podemos perceber que a assessoria técnica praticada rompe barreiras rígidas entre conhecimento técnico e conhecimento dos agricultores. Isso porque as inovações ensinadas são, em sua maioria, soluções de convivência com o se- 
miárido já presentes na região, sejam costumeiras ou criadas pontualmente por agricultores, algumas vezes transformadas presentemente ou no passado por técnicos. O trabalho de assessoria consiste em fazer circular de forma criativa estas inovações. O próprio mito de origem das cisternas de placa ${ }^{5}$ indica um processo de circulação criativa das inovações dá conta desta questão: o modelo de cisternas adotado pelo P1MC foi criado por um emigrante sergipano que, ao retornar de São Paulo, produziu esta inovação, que foi apropriada pelo movimento social, por técnicos e, em última instância pelo Estado, para sua difusão. E que a partir desta difusão, vem sendo novamente modificada com novas inovações. Joelma tem para si clareza deste processo:

Uma boa parte [das técnicas aprendidas com o Sabiá] saiu das experiências dos agricultores mesmo. Da cisterna, por exemplo. Foi um agricultor que foi pra São Paulo trabalhar, chegou lá viu uns prédios grandes e o povo fazendo aquelas cisternas de tijolo e não sei o que, e armazenava a água da chuva. Aí ele disse que achou interessante: 'Mas é engraçado, o sertão da gente precisa muito desse jeito de guardar água.' Eaí lá era de tijolo, quadrada, e aqui quando ele chegou, ele... faz como o ditado: ele pegou informação de lá e criou com a dele e tentou e deu certo. Fez com placa de cimento e areia, e criou a cisterna de beber, de placa, com capacidade para 16 mil litros de água. Ea gente sabe que foi um agricultor, que saiu daqui para ganhar a vida lá fora, mas que voltou e adaptou o conhecimento dele lá e o que ele viu de diferente nessa questão de armazenar água e está aía cisterna que deu certo. Do mesmo jeito são as práticas do dia a dia (...) Eu acho que tudo que a gente vêm aprendendo, a gente vêm aprendendo da maneira e do jeito que todo mundo começa, experimentando. Fazendo e experimentando, fazendo e experimentando. (Joelma, entrevista em abril de 2012).

Assim, só é possível analisar as práticas de conhecimento agroecológicas em Cumaru se as entendermos como híbridas e dinâmicas. O hibridismo vai ainda além do formato da assessoria em si. Em Cumaru, por exemplo, Rosana, uma jovem de uma das famílias do grupo agroecológico, a partir de seu envolvimento com o trabalho e a conclusão de estudo formal, passou a integrar a equipe de assessoria do Sabiá.

O caráter dinâmico das práticas de conhecimento consiste na ideia de que o que é aprendido é um modelo para o que quem aprende fará, mas é da natureza do processo o fato de que a técnica deve ser adaptada às condições locais, materiais disponíveis e novos conceitos adicionados pelo aprendiz. Poderíamos dizer, aqui, "que não é uma receita de bolo", como se costuma dizer. Pelo contrário, porém, tudo ocorre exatamente como uma receita de bolo: uma pessoa vê a outra fazer, pede a receita, mas, na hora de praticar
5 A criação das cisternas de placa parece datar do ano de 1955. Segundo Neves et al (2010), "A cisterna de placas foi inventada por Manoel Apolônio de Carvalho, conhecido como $\mathrm{Nel}$, agricultor sergipano do município de Simão Dias. Nel trabalhou em São Paulo como pedreiro na construção de piscinas, quando aprendeu a utilizar placas de cimento pré-moldadas. Ao voltar ao Nordeste, valeu-se dos aprendizados técnicos que adquiriu nessa fase da vida para criar um novo modelo de cisterna de forma cilíndrica, com placas pré-moldadas curvadas. Nos últimos dez anos, o conhecimento popular continuou a aprimorar essa tecnologia, incorporando algumas melhorias a partir da experiência dos muitos pedreiros, animadores e coordenadores do P1MC." 
aquele conhecimento, é comum que realize adaptações, produzindo resultado diverso, muitas vezes resultando em uma nova receita, derivada, mas diferente, da aprendida. Segundo Ingold, uma receita escrita num livro não é conhecimento em si, mas uma série de referências que mostram o caminho para que o cozinheiro possa, a partir de suas percepções e atenção, praticar habilidades culinárias que espera-se terem sido previamente desenvolvidas. A receita seria, nesse caso, análoga a um mapa, que em si não é suficiente para se trilhar um caminho (Ingold 2000: 219).

Vejamos então como Joelma explica a produção e circulação do conhecimento.

Todo mundo vai inovando, todo mundo vai melhorando, cada um vai dando uma receitinha para estar melhorando isso que vocêjá está fazendo. Não tem um manual de instrução não: fazer muda é desse jeito, fazer canteiro é desse jeito. Cada um vai fazendo de um jeito. Nivá tem um jeito de fazer canteiro, Seu Luís tem outro, aí outro tem outro. Cada um vai adaptando, vai melhorando. (...) Se vai dando certo, vai levando em frente. Se vai dando errado, vamos tentar corrigir onde é que está dando errado. Mas é tudo da experiência deles que estão fazendo. (Joelma, entrevista em abril de 2012).

Quando eu vou lá para João eu também gosto muito, porque o esforço de joão anima a gente, sabe? (...) Ele inventou um veneno de feijão pardo, veneno sem coisa química, viu? Veneno natural. Ele pegou o feijão pardo branco... um dia desse ele até mostrou aos meninos do Sabiá quando os meninos chegaram lá, os meninos chega ficaram... 'Olha, Joelma, eu estava sofrendo que só com umas lagartinhas atacando minhas laranjas. Ai peguei o feijão pardo, botei numa garrafa d'água, tampei, deixei lá.' Aí eu disse: 'Oh João, não explodiu, não?' Porque ele fermenta, né? Aí ele disse: 'Não, tampei bem tampado, de vez em quando eu ia lá e dava uma apertadinha, a frouxava a tampa, saia um bocado do gáse deixava lá. Mas Joelma, mas depois de um tempo eu coei' Que ele amassou, né? Primeiro ele botou de molho, depois ele amassou o caroço do feijão que dentro da água ele ficou mole, coou e botou manipueira. Tu sabe o que é manipueira? Que é da mandioca. Misturou na água do feijão. Disse: 'Mas Joelma, mas deu um veneno bom danado, não tinha bichinho que atacasse mais'. Eaí você vê, a partir da necessidade dele, né? Ele disse: 'Oxe, eu não vou comprar veneno, nada. Nem vou comprar veneno nem quero usar veneno, então eu vou tentar controlar ou cuidar delas (...) [com] o que eu tenho'. Aí ele pegou e inventou isso. A manipueira ele já tinha escutado dizer que servia para essas coisas, para você misturar com fumo ou com outras coisas e tentar aguar. (Joelma, entrevista em abril de 2012).

Tudo que eu aprendo, eu ensino. Eu não tenho história de dizer assim 'não, essa 
informação eu não vou passar não, pra quê??'. Não, de jeito nenhum. Principalmente se for uma coisa boa, que deu certo pra gente. Eu só não gosto de passar aquilo que não teve um resultado tão bom, não gosto. Mas tudo que a gente aprendeu, tudo que tem de informação, que a gente fez e deu certo, eu quero que o povo faça também. Porque, senão, qualé a graça? A gente tem uma informação, se dá bem numa determinada coisa, e não querer que os outros também tenham o mesmo resultado? Qual o futuro que vai ter? Qual é a graça do trabaIho? É quando você começa a ver os resultados. Se você não passa as informações, como é que o povo vai ter os resultados? Não vai ter. Eu prefiro passar tudo.

(Joelma, entrevista em abril de 2012).

Assim, percebemos que as práticas de conhecimento agroecológicos no contexto estudado circulam por uma espécie de difusão criativa (para usar uma expressão que relativize a ideia de difusão). Para que o circuito aconteça, é ingrediente fundamental que ocorra a livre circulação de práticas de conhecimento entre os agricultores.

Em resumo, as redes de práticas de conhecimentos no circuito dos agricultores agroecológicos em Cumaru baseia-se em uma aproximação das relações costumeiras de reciprocidade com uma ética agroecológica de reciprocidade na relação natureza/cultura em que pessoas, plantas, animais e solo são agentes. Para que o circuito aconteça, a livre circulação dos conhecimentos entre os agricultores, em caráter de difusão criativa por meio de intercâmbio e experiências, é ingrediente fundamental. É o que afirma Joelma no fragmento abaixo.

Além, disso, é importante acrescentar que as práticas dos agricultores agroecológicos de Cumaru adicionam às relações costumeiras que descrevemos, pautadas no parentesco e na vizinhança ${ }^{6}$, um certo conceito de natureza, promovido pelos movimentos agroecológicos. Nessa perspectiva, o solo, os animais de criação, os insetos e as plantas cultivadas ou espontâneas seriam todos agentes, e não objetos; e um trato adequado à agricultura e pecuária seria aquele em que a convivência entre as pessoas e os diversos seres que coabitam o local se desse de maneira equilibrada. Entende-se, assim, que, no caso de um convívio equilibrado, a cooperação resulte em ganhos recíprocos.

Tudo se dá como se a dinâmica preferencial dos ecossistemas fosse sinérgica e o agricultor devesse agir como parte dessa sinergia. Ou seja, do modo como os agricultores agroecológicos de Cumaru praticam seus conhecimentos, o agricultor faz parte de uma rede de reciprocidade com a natureza, numa perspectiva que situa a relação entre o agricultor, suas lavouras e os outros componentes do agroecossistema numa chave relacional, em que a reciprocidade depende do conceito de equilíbrio. Essa perspectiva é bastante clara nas narrativas de Joelma, como mostram os fragmentos a seguir.
6 Vimos, do ponto de vista etnográfico, como as relações costumeiras pautadas no parentesco e vizinhança foram importantes para a formação da rede de agricultores que descrevemos em Cumaru. Estas modalidades de relações são fartamente descritos na antropologia rural brasileira (Candido, 1964; Moura, 1978; Sigaud, 1979; Almeida, 1986; 2007; Woortman e Woortmann, 1997; Brandão, 1999). Neste trabalho não temos o objetivo de descrevê-las, até mesmo por questões metodológicas, já que nosso universo de pesquisa são as práticas de conhecimento da rede de agricultores agroecológicos, não todo o universo rural de Cumaru. 
Este circuito tem base numa aproximação entre as relações baseadas em parentesco, compadrio e vizinhança presentes nas redes de relações sociais rurais no semiárido (Sabourin, 2009) e a ética de reciprocidade entre agricultores e natureza promovidas pelos movimentos agroecológicos, que problematiza a própria divisão natureza/cultura em termos de analogia com a divisão sujeito/ objeto. Em ambos os casos (cooperação entre agricultores e cooperação entre agricultor e natureza), a cooperação resulta em ganhos recíprocos. A convergência entre essas duas modalidades de relação é clara na fala de Joelma, como mostram os fragmentos a seguir.

Aí a gente foi vendo que, rapaz, a gente não pode plantar somente feijão, milho e mamão não. Que é o que dava alimento diretamente à gente. Mas a terra também precisa. Na medida em que a gente vai trabal hando com ela e vai plantando as coisas, a gente vai vendo que ela vai dando um retorno, né? Vai produzindo mais; ela vai ficando mais forte; as espigas de milho deixam de ser uma cambotinhas pra ser uma espiga bonita, boa; os pés de mamão deixam de produzir uns mamões pequeninhos e vai produzindo mamão. Até, muitas vezes, pensam que é porque a gente coloca adubo, essas coisas, mas não é. É ela [a terra] que vai se recuperando e vai dando, automaticamente, o retorno. A gente foi vendo que ela foi melhorando. (...) Aí a gente viu, no primeiro inverno que a gente teve e plantou uma quantidade bem grande de coisa misturada, que de cada coisa tinha um pouco. Tipo, tinha milho, tinha feijão, tinha fava, tinha macaxeira (que no início a gente plantou muita macaxeira aqui), ai tinhas as outras coisas, tinha as flores das abelhas, de manhãzinha, no tempo da florada, era uma zoada, porque ela viam aqui pro terreno. Quatro horas da manhã, quando você se acordava, elas zuииииum, fazendo com aquele barulho, nas flores da plantas. Até os pés de palma, que estavam bem pertinho, ou na mesma cova podia ser de aroeira, podia ser uma estaca de gliricídia, o bicho crescia, como se eles estivesse disputando: 'Quem cresce mais, eu ou tu?'. (Joelma, entrevista em novembro de 2011).

No início a gente teve problema com lagarta, hoje a gente não tem mais. (...) No ano passado deu uma lagarta no feijão do povo por aí, ao redor, principalmente pardo. Aqui elas não atacaram. Atacaram sabe o que? Atacaram a folha do jerimum, da batata, das outras coisas, do guandu. Mas muito pouco milho e feijão. Então isso quer dizer que eles estão se equilibrando né? (...) Porque elas tinham opção. Se não tivesse, elas tinham atacado. Mas como já tinha, aí elas não atacam mais como atacavam no início, de jeito nenhum. (...). Aí à medida que a natureza vai se recompondo, aí [a lagarta vai] procurando o habitat dela normal, comendo as coisas que ela tem como preferência. Enão, por falta de opção, a tacar tudo e comer as coisas que a gente não quer. A gente tem observado 
com o passar do tempo que a gente não tem tanto problema como a gente tinha antes. (Joelma, entrevista em abril de 2012)

Nossa pesquisa indica portanto que um dos efeitos locais, em Cumaru, da conformação desta rede agroecológica de convivência do semiárido foi a produção de uma sensibilização dos sentidos dos agricultores na percepção da condição ativa das espécies vegetais e animais na produção da paisagem. Estas práticas de conhecimento produziram, neste caso, uma certa ética da sinergia entre agricultores e cultivos agropecuários.

A forma de desenvolver inovações, nesta perspectiva, é o aprendizado de agricultor a agricultor, ou de técnico para agricultor, não a partir de um protocolo fechado, mas de um processo que só se dá quando atualizado e modificado experiencialmente pelo agricultor. Chamamos aqui este processo de difusão criativa, para diferenciá-lo da perspectiva da agronomia dominante que se refere à passagem de conhecimento técnico das agências e empresas de pesquisa e tecnologia para os agricultores como pacotes tecnológicos, ou seja, protocolos fechados que deve-se reproduzir mecanicamente. A difusão criativa ocorre, portanto, não como resultado de uma transmissão de representações, mas pela educação da atenção (Cibson, 1979; Ingold, 2010)․․

Dito isto, vale a pena nos perguntarmos sobre como esta forma de produzir conhecimentos (e a lógica interna de acesso a ele) se relaciona com o debate sobre o acesso ao conhecimento tradicional sobre a biodiversidade. Vale então neste momento uma nota sobre o caráter tradicional das práticas agroecológicas.

\section{CONHECIMENTOS AGROECOLÓGICOS SÃO CONHECIMENTOS TRADICIONAIS?}

Tradicionalidade é um daqueles conceitos que, da mesma forma como raça e cultura, passaram a ter importância política e jurídica após tornarem-se datados na teoria social. O retorno destes conceitos, pela via dos outros, torna urgente uma reanálise, de cunho etnográfico (Carneiro da Cunha, 2009). Não há espaço aqui para uma revisão do conceito de tradicional. O fato é que as expressões povos (ou comunidades, ou populações) tradicionais e conhecimentos tradicionais passaram a povoar discursos oficiais nacionais e internacionais e também os discursos de grupos locais.

O conceito que classificamos "datado" de tradicionalidade é aquele essencialista, que define um conhecimento ou grupo tradicional como referenciado por valores rígidos e imemoriais, passíveis seja de modernização ou de preservação, mas sem lugar ativo nas dinâmicas sociais contemporâneas (na versão desenvolvimentista) de modernização ou (na versão patrimonialista) de preservação.

Se nos munirmos desta perspectiva, os conhecimentos tradicionais seriam
7 Na apresentação oral de uma versão preliminar deste artigo, a antropóloga Dominique Gallois comentou que as formas tradicionais de produção de conhecimento invariavelmente circulam no modelo que definimos aqui como difusão criativa. Assumindo essa hipótese, desconfiamos ainda que raramente agricultores familiares utilizam os pacotes tecnológicos apresentados por corporações e governos de outra maneira que não pela difusão criativa. Este fato, entretanto, gera dissonâncias: como são privados de conhecer os processos envolvidos nos receituários e técnicas indicadas pelas empresas de agronegócio, muitas vezes os resultados dessa difusão criativa são desastrosos para a saúde, para o solo a para a água, sendo criticados pelos produtores $\mathrm{e}$ difusores destes pacotes como ignorância dos agricultores, ou mau uso dos agroquímicos. 
corpos de conhecimentos ancestrais desenvolvidos ao longo de muitas gerações por grupos fechados e autocontidos, que ocupam uma porção territorial delimitada. Nesse caso, os conhecimentos dos agricultores de Cumaru não seriam tradicionais e nada teriam a ver com o debate em torno da proteção jurídica dos grupos "detentores" de tais conhecimentos.

Ocorre que a reivindicação de tradicionalidade é fato recente e reflete uma necessidade de defesa política dos outros em relação à hegemonia do conhecimento científico e das formas mercantis de apropriação das paisagens e da biologia (Carneiro da Cunha, 2009; Silveira, 2011). O conceito de tradicional passa a ser antropologicamente datado à medida em que uma profusão de estudos mostram que, caso exista uma divisão entre o tradicional e o moderno, ela não reside numa oposição entre o estático e o dinâmico, entre o conservador e o progressista. Mais útil do que estas oposições nos é a ideia de pensamento selvagem e pensamento domesticado (Levi-Strauss, 1989), como modelos lógicos que regem as práticas de conhecimento. $E$, ademais, em tempos em que se conclui que "jamais fomos modernos" (Latour, 1994), podemos perceber que as práticas de conhecimento ditas modernas também têm uma dimensão encoberta de pensamento selvagem (nas palavras de Levis-Strauss) ou de hibridismo (nas palavras de Latour), inclusive a prática científica (Silveira, 2011).

De fato, a ecologia política dos conhecimentos tradicionais no Brasil mostra quão problemática é a versão essencialista de tradicionalidade em sua aplicação política. Baptista (2009) acompanhou experiências práticas de contratos de repartição de benefícios oriundos dos conhecimentos tradicionais associados à biodiversidade no Brasil apresentadas ao Conselho de Gestão do Patrimônio Cenético (CGEN). Sua conclusão é a de que quando parte do pressuposto de que um grupo uniforme sediado em um local delimitado é detentor de um conjunto delimitado de conhecimentos, surgem paradoxos que dificultam a tomada de decisões políticas.

Dentre os exemplos de processos analisados pelo CCEN com tentativas de definir, para fins contratuais, a noção de quem é o grupo ou são os grupos detentores de certos conhecimentos, estão o projeto "Etnobiologia, conservação e de recursos genéticos e bem-estar a limentar da comunidade indígena Krahô", coordenado pela Embrapa; a relação da empresa Natura e as ervateiras do Mercado Ver-o-Peso, em Belém; e a pesquisa de uma universidade na prospecção de soro para picada de aranha marrom, espécie que constitui um problema de saúde pública na região metropolitana de Curitiba (Baptista, 2009).

Podemos acrescentar aí um outro caso, o do Projeto Kampô, fora do âmbito do CCEN, coordenado pelo Ministério do Meio Ambiente por solicitação do povo Katukina. Este projeto visava criar um modelo de bioprospecção com repartição justa de benefícios aos detentores do conhecimento a respeito da secreção 
epidérmica do sapo kampô (Phyllomedusa spp.), conhecida como vacina do sapo, usado por uma série de grupos indígenas amazônicos e recentemente popularizado em meio não indígena (Martins, 2006; Carneiro da Cunha, 2009; Lima, 2009). Lima conclui que:

quando visto a partir do prisma dos direitos de propriedade intelectual, ao invés de um 'caso-piloto' para fazer operativa a legislação sobre o assunto, o Projeto Kampô acabou se mostrando como um caso-limite, tamanha a extensão dos problemas que precisariam ser superados caso fossem bem-sucedidos os esforços então mobilizados. (Lima, 2009: 64).

A principal dificuldade de aplicação (e formulação) deste tipo de proposta, oriundo dos mecanismos de proteção aos conhecimentos tradicionais previstos pela Convenção da Diversidade Biológica, não está, obviamente, apenas no plano do conceito de tradicionalidade, mas de sua relação com uma perspectiva contratualista, que muitas vezes abarca certos processos que são intraduzíveis na lógica da propriedade intelectual. A criação de sistemas sui generis de propriedade intelectual continua, portanto, como um desafio, como discutiremos abaixo.

Voltemos à natureza dos conhecimentos tradicionais. Carneiro da Cunha (2009) afirma que não há conhecimento tradicional enquanto unidade. Este só é visto assim em contraste com o conhecimento científico, cujos praticantes o pretendem uno e universal. Soma-se a isso a dificuldade que os Estados Nacionais têm em lidar com a diversidade (Silveira, 2010). Carneiro da Cunha (2009) postula, então, a existência uma multiplicidade de regimes de conhecimentos tradicionais, cada qual com seus critérios de produção e validação. Alinha-se, então, com uma perspectiva que trata de regimes de conhecimento tradicional, sendo os conhecimentos tradicionais definidos enquanto procedimentos:

Tem se firmado na literatura jurídica e nas declarações de movimentos indígenas internacionais a noção de que os conhecimentos tradicionais não são simplesmente um corpus estabilizado de origem imemorial, e sim conjuntos duradouros de formas particulares de gerar conhecimentos. O conhecimento tradicional, nessa visão, não é necessariamente antigo. Tradicionais são seus procedimentossuas formas, não seus referentes. (Carneiro da Cunha, 2009: 364)

Esta digressão sobre a questão legal dos conhecimentos tradicionais nos é útil, agora, para retornar às práticas de conhecimento dos agricultores agroecológicos de Cumaru. A forma como as definimos acima, a partir da etnografia (livre circulação dos conhecimentos entre os agricultores, em caráter de difusão criativa por meio de intercâmbio e experiências e baseado noções de reciprocidade 
costumeiras, educação da atenção, ética ambientalista e redes colaborativas) determina um regime de conhecimentos que constitui um outro do conhecimento científico e das relações de apropriação mercantil. A lógica da produção de novidades por parte dos agricultores agroecológicos de Cumaru escapa do que Leach (2004:165) classifica como "o mito euro-americano da criatividade competitiva" baseado na noção internacionalizada de propriedade intelectual.

O tipo de assessoria evidenciado na atuação dos técnicos do Centro Sabiá (e por extensão, de uma série de outras organizações com atuação de natureza semelhante) vem a reforçar procedimentos dos sistemas locais de praticar conhecimentos e apresenta novidades de maneira não-colonizadora. Parece se aproximar do que Boaventura de Sousa Santos (2005; 2006) denomina ecologia de saberes, uma conformação relacional de conhecimentos onde não há centralidade das práticas científicas, evitando-se assim solapar a diversidade de saberes. Em outras palavras, parece haver uma "ação política (em uma política das pessoas e das coisas) que se baseie na ideia de simetria" (Silveira 2011: 233).

Neste circuito, portanto, nem todas as técnicas que "vem de fora" são incorporadas, e o que é incorporado o é dentro da lógica do circuito. Quanto a isso, vejamos um último relato etnográfico. No início de sua trajetória com a agroecologia, Roberto e Joelma tiveram sua lavoura de fava, em flor, atacada por uma espécie de percevejo. Como passava por um período sem contato com o técnico do Centro Sabiá, consultou um técnico do Instituto Agronômico de Pernambuco (IPA), que atualmente é o órgão estadual de assistência técnica rural. O técnico indicou que usasse um "inseticida bom" que ele tinha na sede do IPA e que traria na próxima visita. Joelma conta que não gostou da ideia, mas acabou aceitando a oferta do técnico.

Eu disse, 'Virgem Maria! É de mato? É natural? Foram vocês que criaram? Foram vocês que fizeram do mato, de alguma planta?'. Ele disse: 'Não, é o que a instituição trabalha, trabalha com isso, com essas coisas'. Aí eu disse: 'Ave Maria, não queria não. O senhor não conhece nenhuma outra coisa? Tipo, se a gente usar uma planta, que a gente não tenha, mas se o senhor conhecer aonde tem eu peço pro senhor trazer e a gente faz.'. Ai ele disse: 'Não, conheço muita coisa, não'. Era um [técnico] daqueles bem antigos, bem tradicionais, dos primeiros da assistência técnica do Brasil. Aí eu disse: 'Pois traga'. Aí ele trouxe. Quando eu cheguei aqui com ele, que Roberto abriu, disse: 'Oxe, vou usar isso, não. O bicho fede, é uma catinga que chega deixa a gente tonto. Só em você abrir a tampa, o lacre do bicho.' Aí eu disse: 'É, então não vamos botar não'. (Joelma, entrevista em novembro de 2011).

Dias depois de receber o inseticida e decidir não usá-lo, o casal foi visitado pelo 
técnico do Sabiá, que propôs uma receita caseira para espantar os percevejos.

Na semana seguinte o técnico do Sabiá chegou, que era a té o Galego: Vilmar. Aíeu disse: 'Vilmar, eu pedi um remédio ao técnico do IPA e ele me trouxe esse negócio aqui e a gente não quer usar isso aqui não.' (...). Aí ele disse: 'Sabe o que você vai fazer? Você pega os besouros, junta um bocado bom, bota numa garrafa pet, pegue um pau e pise. Mate tudinho. Bote água dentro, coe, bote dentro da bomba, do pulverizador, bote uns cinco litros de água, dependendo da quantidade de besouro que você tiver tirado, e agoe, ou pulverize né? A fava.' Mas menina, o bicho não suporta o próprio cheiro dele. Já pensasse? Porque é assim, se a gente não mexer com ele, ele não fede, ele não tem aquele cheiro forte, mas se você mexer com ele, ele solta um cheiro bem forte. Ai a gente fez do mesmo jeito que ele pediu, nunca mais. Não precisou usar veneno. (Joelma, entrevista em novembro de 2011).

Assim, neste caso ocorreu uma recusa em utilizar o agrotóxico fornecido pelo técnico do governo e a preferência pela solução apresentada pelo técnico do Centro Sabiá, por ser uma solução caseira, não tóxica aos agricultores e ao ambiente, e passível de ser replicada domesticamente no futuro. Isto indica que as soluções técnicas que não faziam parte do repertório local são incorporadas seletivamente no regime local de práticas de conhecimento. Da mesma forma, há técnicas aprendidas na televisão, também de forma seletiva:

[O agricultor-experimentador] está sempre experimentando técnica nova, jeito de criar, como cuidar melhor da terra, não sei. É isso que a gente está fazendo no dia a dia. Agora, que a gente está sempre aberto a coisas que venham facilitar. Por exemplo, a gente assiste o Clobo Rural e quando tem uma coisa interessante que a gente sabe que a gente também pode fazer aqui, a gente faz. Eu acho que é experimentar. Um jeito novo de trabal har a terra, uma muda diferente, não sei... agora que se adapte bem. Eeu acho que agricultor agroecológico é sempre agricultor experimentador, não vai ser diferente, não. Porque não é um agricultor pronto, é um agricultor que está sempre criando, experimentando, aprendendo, se informando. (Joelma, abril de 2012).

Em suma, ao descrevermos as redes conformadas pelas práticas de conhecimentos dos agricultores agroecológicos de Cumaru, percebemos a existência de um regime de específico de conhecimento cuja base são as formas costumeiras de relações sociais em interação com uma proposta híbrida, a da agroecologia baseada na convivência com o semiárido. Este tipo de proposta faz sentido para os agricultores que nela se engajam por estabelecer um diálogo produtivo com as lógicas locais. 
Este regime de conhecimento, que produz inovações e que em si pode ser entendido como inovador, constitui, numa perspectiva não-essencialista, um regime do tipo tradicional, em termos de seus procedimentos. A assessoria técnica, que foi fundamental na conformação deste regime, propõe-se a assessorar os agricultores em seus próprios termos, inserindo-se de forma interessante no regime tradicional. Ou seja, é o procedimento contrário das muitas iniciativas existentes, colonizadoras, de treinamento científico de agentes locais. É o avesso disso, a tradicionalização (via um regime tradicional de criatividade) da assistência técnica rural.

\section{ACESSO AOS CONHECIMENTOS AGROECOLÓGICOS}

Tratamos aqui de um ambiente fecundo de práticas colaborativas de convivência com o semiárido, ambiente este que propicia uma forma não apropriativa de gestão da agrobiodiversidade. Nossa tarefa nesta seção conclusiva é discutir as possíveis relações do regime de práticas de conhecimento descrito com o regime de propriedade intelectual.

O uso do termo práticas de conhecimento ao longo do texto não é casual. Ele parte da perspectiva de que os conhecimentos se produzem e reproduzem ao se praticá-los (Law e Mol, 2002; Ingold, 2000; Silveira, 2011). Sob esta perspectiva, os regimes de conhecimento existem, concretamente, enquanto práticas. Assim, para salvaguardar (para usar o termo patrimonialista) este conhecimento é preciso que se assegure a possibilidade de que sejam praticados e suas redes se conformem ${ }^{8}$. Isso significa que os mecanismos de salvaguarda de diferentes regimes de conhecimento devem ser pensados caso a caso. Em termos de políticas públicas isso se torna um grande problema, face à grande dificuldade do Estado Nacional em lidar com (ou regular) a multiplicidade.

No caso estudado, nos parece que o que assegura o circuito é a segurança territorial, a capacidade de armazenamento de água, o incentivo às relações de colaboração costumeiras entre agricultores, a promoção da difusão criativa de conhecimentos, a experimentação, o caráter de código aberto (para usar um termo da informática) da produção de novidades e a manutenção de uma ética de reciprocidade com os não-humanos.

Percebemos na rede de agricultores agroecológicos de Cumaru que a autoria individual das inovações não é relevante. Algumas vezes pode ser identificada, como no caso da origem das cisternas de placa (talvez por ser uma narrativa fundadora e registrada pelas organizações) ou de inovações produzidas por pessoas conectadas entre si diretamente na rede de práticas de conhecimento (o veneno natural inventado por João). Em geral encontramos o registro de com quem aprendeu, mas não do criador. Isso porque as inovações são vistas necessa-
8 Isto não é nenhuma novidade, em termos conceituais. Há mais de dez anos Mauro Almeida e Manuela Carneiro da Cunha faziam este tipo de proposição, defendendo que para que populações tradicionais realizem uso sustentável de áreas florestais com base em práticas passadas de baixo impacto, era preciso incentivar seus modos de vida para que sejam capazes de continuar a fazê-lo no futuro (Almeida e Carneiro da Cunha, 2001). Esta perspectiva de incentivar processos está também nas diretrizes para as políticas federais de patrimônio imaterial no Brasil (IPHAN, 2010). Na prática, porém, parece-nos que estas abordagens tem permanecido isoladas, solapadas por outras políticas guiadas por grandes interesses econômicos e por perspectivas economicistas desenvolvimentistas. 
riamente como produto colaborativo e para fim de uma coletividade difusa, e sua repartição é parte constituinte da lógica produtiva.

Assim, consistiria um paradoxo, neste caso específico, a realização de contratos de repartição de benefícios com base numa autoria individual, ou mesmo de uma coletividade delimitada. Seria, num jargão futebolístico que nos parece apropriado aqui, "jogar contra o patrimônio"9. Explicando melhor: as práticas de conhecimento circulam pela lógica do livre acesso colaborativo da reciprocidade, mesmo quando há dinheiro envolvido, como é o caso dos fundos rotativos solidários ${ }^{10}$ e do processo de construção de cisternas. Os produtos agrícolas (grãos, mel, leite, queijo, carne, etc.) é que circulam pela lógica da troca mercantil. Parece-nos, pois, importante, como ocorre no contexto estudado, assegurar que os conhecimentos circulem e continuem a circular pela lógica da reciprocidade e pela difusão criativa, e que os produtos de troca mercantil sejam valorizados economicamente. Isso é exatamente o que o Centro Sabiá tem feito na região.

No caso de evitar apropriações indébitas das práticas de conhecimento colaborativas pela lógica mercantil privada, parece-nos útil o registro público destes regimes de conhecimento. No Brasil uma iniciativa deste tipo tem sido levada a cabo pelo Ministério da Cultura, no âmbito do Instituto do Patrimônio Artístico Arquitetônico e Arqueológico Nacional (Iphan), desde o início dos anos 2000, com as políticas para salvaguarda do Patrimônio Imaterial (Iphan, 2010). Apesar da proposta clara de assegurar a continuidade dos processos de produção de conhecimentos a serem protegidos, tais políticas, levadas a cabo , têm sido estabelecidas com foco na ideia de bens culturais, que muitas vezes acabam por voltar o olhar para o patrimônio imaterial como coisa, e não como rede. Um processo de registro de patrimônio imaterial que consideramos convergente com as ideias aqui apresentadas é o dos "Sistema Agrícola Tradicional do Rio Negro" (Emperaire, 2010).

Um segundo passo que postulamos, como exercício de imaginação, é o reconhecimento das práticas de conhecimento agrícolas do tipo tradicional, tão impactadas negativamente há décadas pela inclusão forçada na chamada revolução verde, como zonas livres de propriedade intelectuale de segredo industrial. Isto deve ser estendido também a quaisquer novos conhecimentos ou produtos delas derivados.

Por exemplo, um inseticida natural criado no âmbito destas redes poderia eventualmente ser comercializado por uma empresa, mas neste caso deve ser necessariamente feito em código aberto, sendo fornecida no próprio rótulo do produto a receita de como fazê-lo em casa. Um inseticida criado por uma pesquisa que tome como base este inseticida natural, ou seja, uma inovação criada em circuito tradicional, deve ser livre de patenteamento, e parte dos lucros serem destinados a fundos de apoio às práticas originárias destes conhecimentos.
9 Utiliza-se este jargão quando um jogador faz um gol contra seu próprio time.

10 Os fundos rotativos solidários são estratégias de financiamento comunitário baseado em reciprocidade, que abrangem, por exemplo, a construção de cisternas e a compra de pequenos animais. Para mais detalhes, ver Sabourin (2009). 
No caso estudado, estratégias eficientes de repartição de benefícios envolveriam apoio às iniciativas de convivência com o semiárido em curso (financiamento para construção de cisternas, para fundos rotativos solidários, financiamento de intercâmbios), com decisões de aplicação de fundos tomadas nos contextos legítimos de decisão que se conformaram nos últimos anos (organizações locais, entidades de assessoria, Articulação do Semiárido).

Que não soe inocente a proposição de conhecimentos tradicionais como zona livre de propriedade intelectual no cenário da economia mundial. Ela se situa, entretanto, em um panorama mais amplo das transformações mundiais contemporâneas em que a crise das corporações e das economias centrais abre espaço para questionamento dos modelos apropriativos de conhecimento. Assim, a propriedade intelectual em moldes mercantis cria paradoxos e a luta por formas não mercantis e práticas colaborativas ocupa campos diversos de conhecimento como a agricultura, a saúde, a prática científica e a produção de tecnologia da informação. Neste contexto, a rede de convivência com o semiárido e os agricultores agroecológicos de Cumaru constituem vanguarda.

No caso das práticas de agricultura familiar declaradamente agroecológicas (o que implica militância pela abordagem cooperativa e contra a indústria agroquímica e os pacotes tecnológicos), o código aberto de práticas acessíveis ao agricultor parece suficiente para criar uma alternativa viável aos pacotes tecnológicos. Sabemos que este não é o caso, por exemplo, da indústria farmacêutica.

Finalmente, resta dizer que, no contexto do Semiárido nordestino, em que as práticas de conhecimento dos agricultores de Cumaru se inserem, outras questões aparecem para os agricultores e organizações como urgentes, para além das questões de autoria, acesso e repartição de benefícios.

No início deste texto, contamos como o início das atividades agroecológicas de Roberto e Joelma iniciou-se pelas redes formadas pela obtenção de estratégias de armazenamento de água baseadas em relações de reciprocidade. Esta perspectiva, a da convivência com o semiárido, se confronta com os projetos de modernização do sertão via agronegócio da irrigação, cujo ícone é o projeto de Transposição do Rio São Francisco, levado a cabo no mesmo período da pesquisa.

Vimos Joelma militando pela diversificação como forma de equilíbrio das pragas na propriedade e como estratégia de vida e negando o uso de venenos. Esta postura é comum em agricultores familiares agroecológicos. Está presente porque os circuitos colaborativos agroecológicos baseados em diversidade são prejudicados pelas formas homogeneizantes e privatistas da industrialização da agricultura. Isso se reflete nas mobilizações coletivas atuais no semiárido pelas sementes crioulas e contra sementes transgênicas, pela construção de alternativas ao uso de agroquímicos.

Por fim, narramos, no início deste artigo, como Joelma e Roberto puderam 
estabelecer uma organização da produção que julgam adequada pela possibilidade de aumento de sua propriedade de meio hectare para sete hectares. Isto se relaciona a um último grande entrave à manutenção dos circuitos agroecológicos, a insegurança territorial, problema histórico dos moradores pobres do semiárido nordestino (e não só desta região). Concordamos aqui com o sentido geral da formulação de Ellen e Klaas Woortmann, quando afirmam que "ser sitiante, ser dono da terra é condição básica de ser liberto, juntamente com o domínio tanto cognitivo como simbólico do saber que orienta o processo de trabaIho" (Woortmann e Woortmann, 1997: 44). Explica-se aí o engajamento das organizações militantes da convivência com o semiárido em questões territoriais, tais como a demarcação de territórios indígenas e quilombolas, e pela reforma agrária. A segurança territorial, na perspectiva adotada aqui, é também uma das chaves para a existência das condições da prática relacional de conhecimentos agroecológicos. Assim, a luta por segurança territorial, seguindo a proposta de Almeida (2007), escapa de uma luta por direitos genéricos de cidadania, mas inclui nesta luta direitos sobre modos de existência diversos.

Pedro Castelo Branco Silveira é Doutor em Ciências Sociais pela Universidade Estadual de Campinas (2008) e é Pesquisador da Fundação Joaquim Nabuco desde 2007.

Júlia Costa Rosas é graduada em Ciências Sociais pela Universidade Federal de Pernambuco (2012) e em Ciências Biológicas pela Universidade Católica de Pernambuco (2011). Atualmente é mestranda em Agroecologia para a Sustentabilidade Rural na Universidade Internacional de Andalucia. Desde 2013 dá Assessoria Técnica a agricultores familiares no Programa Um Milhão de Cisternas.

\section{REFERÊNCIAS BIBLIOCRÁFICAS}

AB'SÁBER, Aziz

2003 Os domínios da natureza no Brasil: potencialidades paisagísticas. Cotia-SP, Ateliê editorial. 
ALMEIDA, Mauro W. B de

1986 "Redescobrindo a família rural". Revista Brasileira de Ciências Sociais, v. 1, n.1: 66-83.

2007 "Narrativas agrárias e a morte do campesinato". Ruris, v. 1, n. 2.

ALMEIDA, Mauro W. B. e CARNEIRO DA CUNHA, Manuela

2001 "Clobal Environmental Changes and Traditional Populations". In HOCAN, Daniel ]. e TOLMASQUIM, Maurício Tiomno (orgs.). Human

Dimension of Clobal Environmental Changes: Brazilian Perspectives.

Rio de Janeiro, Academia Brasileira de Ciência. pp. 79-98.

ALTIERI, Miguel e TOLEDO, Victor

2011 "The Agroecological Revolution in Latin America: Rescuing Nature, Ensuring Food Sovereignty and Empowering Peasants". Journal Peasant Studies, v. 38, n. 3.

BAPTISTA, Fernando Mathias

2009 "Os impasses da abordagem contratualista da política de repartição de benefícios no Brasil: algumas lições aprendidas no CCEN e os caminhos de sua superação". In KISHI, Sandra A. S. e KLEBA, John B. (orgs.). Dilemas do acesso à biodiversidade e aos conhecimentos tradicionais. Belo Horizonte, Editora Fórum.

BRANDÃO, Carlos R.

1999 O afeto da terra: imaginários, sociabilidades e motivações de relacionamentos com a natureza e o meio ambiente entre agricultores e criadores sitiantes do bairro dos Pretos, nas encostas paulistas da serra da Mantiqueira, em Joanópolis. Campinas-SP, Ed. Unicamp.

BRITO, Luiza T. L.; SILVA, Dinarte A.; CAVALCANTI, Nilton de B.; DOS ANJOS, José B.; e RECO, Maurício M.

1999 "Alternativa tecnológica para aumentar a disponibilidade de água no semiárido". Revista Brasileira de Engenharia Agrícola e Ambiental, v.3, n.1: 111-115.

CANDIDO, Antonio

(1964) 2001 Os parceiros do Rio Bonito. São Paulo, Ed. 34.

CARNEIRO DA CUNHA, Manuela

2009 Cultura com aspas. São Paulo, Cia das Letras. 
DUQUE, Ghislaine

2008 "Conviver com a seca: contribuição da Articulação do Semi-Árido/ASA para o desenvolvimento sustentável".

Desenvolvimento e Meio Ambiente, n. 17: 133-140.

EMPERAIRE, Laure (org.)

2010 Dossiê de registro do Sistema Agrícola Tradicional do Rio Negro. Brasília, ACIMRN / IPHAN / IRD / Unicamp-CNPq, 235 p. (textos de Manuela Carneiro da Cunha, Laure Emperaire, Esther Katz, Ana Gita de Oliveira, Juliana Santilli, Lúcia Hussak van Velthem). Disponível em: http://www.iphan.gov.br, acesso em fevereiro de 2018.

GIBSON, James. ].

1979 The Ecological Approach to Visual Perception. Boston, Houghton Mifflin.

HOCDÉ, Henri

1999 A lógica dos agricultores experimentadores: o caso da América Central. Metodologias Participativas. Rio de Janeiro, AS-PTA.

INCOLD, Tim

2000 The Perception of the Environment. Nova York, Routledge.

2010 "Da transmissão de representações à educação da atenção". Revista Educação, v. 33, n. 1: 6-25.

INGOLD, Tim e KURTILLA, Terhi

2000 "Perceiving the Environment in Finnish Lapland". Body and Society, v.6, n.3-4.

INSTITUTO do Patrimônio Artístico Arquitetônico e Arqueológico Nacional 2010 Os sambas, as rodas, o bumbas, os meus e os bois: princípios, ações e resultados da política de salvaguarda do patrimônio cultural imaterial no Brasil 2003-2010. Brasília, Iphan.

KISHI, Sandra A. S. e KLEBA, John B.

2009 Dilemas do acesso à biodiversidade e aos conhecimentos tradicionais. Belo Horizonte, Editora Fórum.

LATOUR, Bruno

1994 Jamais fomos modernos. São Paulo, ed. 34. 
LAW, John e MOL, Annemarie (orgs.)

2002 Complexities: social studies of knowledge practices.

Durham, Duke University Press.

LEACH, James

2004 "Modes of creativity". In HIRSCH, Eric e STRATHERN, Marilyn (orgs.). Transactions and Creations: Property Debates and The Stimulus of Melanesia. Oxford, Berghahn Books.

LÉVIS STRAUSS, Claude

1989 Opensamento selvagem. Campinas, Papyrus.

LIMA, Edilene C.

2009 "Entre o mercado esotérico e os direitos de propriedade intelectual: o caso do kampô". In KISHI, Sandra A. S. e KLEBA, John B. (orgs.). Dilemas do acesso à biodiversidade e aos conhecimentos tradicionais. Belo Horizonte, Editora Fórum.

MARTINS, Homero M.

2006 Os katukina e o kampô: aspectos etnogáficos da construção de um projeto de acesso aos conhecimentos tradicionais. Brasília, dissertação de mestrado, Universidade de Brasília.

MOURA, Margarida M.

1978 Os herdeiros da terra. Parentesco e herança numa área rural. São Paulo, Hucitec.

NEVES, Rafael S.; MEDEIROS, Jean Carlos A; SILVEIRA, Sandra M. B.; e MORAIS, Carlos M. M.

2010 "Programa um milhão de cisternas: guardando água para semear vida e colher cidadania". Agriculturas, v. 7, n. 3.

NYGREN, Anja

1999 "Local Knowledge in the Environment-Development Discourse: From Dichotomies to Situated Knowledge". Critique of Anthropology, v.19, n. 3.

PINTO, Edilene B.

2004 A educação ambiental em área semi-árida da Bahia: uma contribuição para a gestão. Recife, dissertação de mestrado profissionalizante, Universidade Federal de Pernambuco. 


\section{SABOURIN, Eric}

2009 Camponeses do Brasil: entre a troca mercantile a reciprocidade. Rio de Janeiro, Ed. Garamond.

SABOURIN, Eric; CARON, Patrick; e SILVA, Pedro Carlos Cama da

2009 'O manejo dos 'fundos de pasto' no nordeste baiano: um exemplo de reforma agrária sustentável". Raizes- Revista de ciências sociais e econômicas, Campina Grande, Universidade Federal da Paraíba, v. 18, n. 20: 90-102.

SANTILLI, Juliana

2005 Socioambientalismo e novos direitos: proteção jurídica à diversidade biológica e cultural. São Paulo, Peirópolis/ISA.

2009 Agrobiodiversidade e os direitos dos agricultores. São Paulo, Peirópolis.

SANTOS, Boaventura S.

2005 Semear outras soluções: os caminhos da biodiversidade e dos conhecimentos rivais. Rio de Janeiro, Civilização Brasileira.

2006 A gramática do tempo: para uma nova cultura política. São Paulo, Cortez.

SICAUD Lygia

1979 Os clandestinos e os direitos. Estudo sobre trabalhadores da canade-açúcar de Pernambuco. São Paulo, Duas Cidades.

SILVEIRA, Pedro C. B.

2010 "Florestas e lutas por reconhecimento: território, identidades e direitos na Mata Atlântica brasileira". Campos, v. 11, n. 2: 95-112.

2011 "Conhecimentos científicos, conhecimentos locais e hibridismo: por uma etnografia simétrica da paisagem". R@U, v.3, n.1: 212-235.

STRATHERN, Marilyn; CARNEIRO DA CUNHA, M.;

DESCOLA, P.; HARVEY, P.; AFONSO, C. A.

1998 "Exploitable Knowledge Belongs to the Creators of It: A Debate". Journal OfThe European Association OfSocial Anthropologists, v. 6, n. 1: 109-126.

WOORTMANN, Ellen F. e WOORTMANN, Klaas A.

1997 O trabalho da terra: a lógica e a simbólica da lavoura camponesa. Brasília, Ed. da UnB. 


\section{ABSTRACT}

This article approaches the contribution of agroecological networks to debates about access to traditional knowledge. We present research about networks of production and circulation of agroecological knowledge in the semi-arid region of Pernambuco State, Northeastern Brazil. These experiences have, as their background, the eco-political framework regionally known as 'convivência com o Semiárido' ('co-existence with the Semi-arid'). They keep off from technological packages and move towards creative and collaborative modes of practicing knowledge.

\section{KEYWORDS}

Collaboration, Traditional Knowledge, Agroecology, Intellectual Property, Caatinga

Recebido em 22 de fevereiro de 2015. Aceito em 20 de junho de 2017. 